\title{
Hans Welzel: una aproximación a su vida y a su obra*
}

\section{Hans Welzel: an approach to his life and work}

\author{
Fernando Velásquez V."
}

Fecha de recibido: 22 de agosto de 2007

Fecha de aprobación: 12 de septiembre de 2007

\section{Resumen}

A partir de la obra de iusfilósofo alemán Hans Welzel, el texto analiza los aportes del pensador alemán al Derecho Penal. Para ello, el texto cuenta con la siguiente estructura: en primer lugar, las ideas centrales de la concepción del profesor Hans Welzel; en segundo lugar, algunas críticas que se han hecho a la persona y a la obra del destacado profesor y una valoración de las mismas; finalmente, se formulan algunas conclusiones para la discusión.

\section{Palabras clave}

Hans Welzel, Derecho Penal, positivismo, derecho y poder, derecho y ciencia.

Este trabajo ya fue publicado en México y aparece en la página web de la Universidad de Fribourg, Suiza. En Colombia no ha sido difundido y la Universidad de Santo Tomás ha querido hacerlo para contribuir al debate académico sobre estas materias.

** $\quad$ Profesor de la Universidad Sergio Arboleda. 


\begin{abstract}
Starting from Hans Welzel's legal-philosophical work, the present article analyses this German thinker's contribution to the development of penal law. The text is structured as follows: Firstly, it presents Welzel's central ideas; secondly, it discusses and evaluates the main points of criticism regarding the person and the work of this outstanding lecturer; thirdly, it draws some conclusions in order to contribute to the academic discussion of Welzel's work.
\end{abstract}

\title{
Keywords
}

Hans Welzel, penal law, positivism, law and order, law and science

\section{INTRODUCCIÓN}

Cuando hace ya un poco más de treinta años -momento en el cual se encontraba en pleno fragor el debate entre causalismo y finalismo- llegaron a mis manos de estudiante ávido de conocimientos los trabajos del gran penalista y iusfilósofo alemán Hans Welzel, nunca imaginé que durante toda mi vida académica me iba a tener que ocupar una y otra vez de su obra; $y$, por supuesto, tampoco pensé que cuando se iba a conmemorar el centenario de su nacimiento -justamente en el momento en que era más álgida en la polémica entre finalismo y funcionalismo- me iba a tocar concurrir, junto con otros colegas, a homenajearlo en México, donde se organizó en 2004 un gran encuentro académico en su memoria.

Pero lo que hoy más me llena de alegría es haber sido invitado hoy, por una persona tan cara a mis afectos y con quien me unen muchos años de franca amistad, como el profesor Ignacio Verdugo Gómez de la Torre, a dictar la "Lección inaugural" de la Maestría en Derecho Penal que administran conjuntamente las universidades de Salamanca y Santo Tomás en nuestro país, la misma que los mentores de este proyecto académico -atendidos los contenidos de su programa académico- han querido que destine para a evaluar la obra de tan emblemático pensador, cuya influencia en Colombia ha sido mayúscula.

\section{SU VIDA Y SUS POSTULADOS BÁSICOS}

Algunos datos biográficos ${ }^{1}$

Hans Welzel nació en Artern/Unstrat (Thüringen) el 25 de marzo de 1904 y murió en Bonn, el 5 de mayo de 1977. A los diecinueve años comienza sus estudios de matemáticas en la Universidad de Jena, los que abandona para dedicarse al Derecho y a la Filosofía en las Universidades de Heidelberg -por la cual desfila un breve lapso- y Jena, con la dirección de los neokantianos B. Bauch y H. Rickert, el fenomenólogo P. F. Linke y el historiador M. Wundt ${ }^{2}$. En la Universidad de Jena, justamente,

\footnotetext{
Véase Recaséns Siches: El pensamiento, tomo II, pp. 922 y ss. Asimismo, como lo reconoce el propio Welzel al prologar la 4a. edición de su obra "El nuevo Sistema del Derecho Penal", recibió influencias de otros importantes pensadores que publicaron sus trabajos entre 1920 y 1930: "Las sugerencias para la formulación de la doctrina de la acción finalista no las recibí de N. Hartmann, sino de la psicología del pensamiento y la primera de ellas, precisamente, de la obra Grundlagen der Denkpsychologie (Fundamentos de la psicología del pensamiento) del filósofo, recién fallecido, Richard Hönigswald. Recibí también otras sugerencias de los trabajos de los psicólogos Kart Bühler, Theodor Erismann, Erich Jaensch, Wilhelm Peters y de los fenómenólogos P. F. Linke y Alexander Pfänder, entre otros" (Véase El nuevo sistema, pp. 28 y 29).
} 
conoce al profesor Hans Albrecht Fischer reputado penalista y filósofo con cuya hija, Sigrid -de credo protestante, mientras él era de origen católico, aunque agnóstico en materias religiosas ${ }^{3}-$, contrae nupcias, y del cual se nutre mucho en aquel momento de su vida. Estudia Derecho Penal con Gerland y Grünhut sin que -como se ha dicho- "esta materia se revelara para él, por aquel entonces, como la disciplina de su especialidad"4.

En 1927, aprueba su primer examen estatal de Derecho, y en 1928, a los 24 años de edad, se doctora con una tesis dedicada a La teoría del Derecho Natural de Samuel Pufendorf. Sólo en 1932 aprueba su segundo exame $n$ de Estado. No obstante, ya desde 1930 empieza a trabajar como profesor asistente de Gotthold Bohne en la Universidad de Köln, y comienza a elaborar su trabajo de habilitación como profesor, intitulado Naturalismo y filosofía de los valores en el Derecho Penal ${ }^{5}$, publicado en 1935, parcialmente traducido al japonés algunos años después.

En 1936, se le designa como profesor interino de la Universidad de Göttingen, en la que un año más tarde se le inviste como profesor extraordinario en la cátedra de Robert von Piel, para enseñar Derecho Penal y Derecho Procesal Penal. En 1940, Welzel es contratado como profesor Ordinario de la misma Universidad para impartir, además, cursos de Filosofía del Derecho e incluso de Derecho Procesal Civil, donde tiene alumnos tan destacados como Günther Stratenwerth y Armin Kaufmann. Allí permanece hasta 1951, luego de haber sido Decano de la Facultad de Derecho tras la guerra.

De su época en Göttingen datan sus trabajos de conjunto Estudios sobre el sistema del Derecho

3 Así Cerezo Mir, en Barquín Sanz: "Conversaciones", en RECPC 03-C3-2001, p. 3, en www.criminet.ugr.es/recpc.

4 Véase Sancinetti en "Biografías", Revista del Colegio Público N 67, en www.cpacf.org.ar, s/p.

5 Veáse: "Naturalismus und Wertphilosophie im Strafrecht", en Abhandlungen zum Strafrecht, pp. 29 y ss.
Penal (1939) y La parte general del Derecho Penal alemán en sus lineamientos (1940), que fue objeto de tres ediciones; lo mismo sucede con las primeras impresiones de su Lehrbuch, destinado tanto a la parte general como a la especial, publicado en 1947, del cual se hicieron once ediciones hasta 1969, con traducciones parciales al español en Argentina ${ }^{6}$ y en Chile (19567, cuarta edición, y $1970^{8}$ undécima edición, ambas sólo en la Parte General). Pero, sobre todo, debe mencionarse su estudio cumbre en el campo de la Filosofía del Derecho, intitulado Derecho Natural y justicia material (1951, también traducido en dos oportunidades al español: 1957 y 1971). Lo mismo puede decirse de su contribución El nuevo Sistema del Derecho Penal (1951), vertida al español en 1964, que recoge de manera didáctica los capítulos centrales de su pensamiento jurídico-penal.

Con posterioridad, entre 1952 y 1974, se traslada como profesor de Derecho Penal y Filosofía del Derecho a la Universidad de Bonn en reemplazo de Alexander Graf zu Dohna, donde labora como primer Director del Instituto de Filosofía del Derecho y Rector de esa casa de estudios. Se inicia así, en plena posguerra y luego de haber obtenido en 1947 un dictamen favorable sobre su vida y su obra -emitido por Rudolf Smend, quien había sido un perseguido por el régimen nazi ${ }^{9}-$ un periodo muy fructífero de su vida académica, que lo lleva a continuar con sus innumerables publicaciones que lo proyectan, más que ningún otro, como el penalista alemán más reconocido

6 Debe recordarse que gracias a la labor del gran iusfilósofo argentino E. Garzón Valdés, sus trabajos destinados a examinar las relaciones entre el Derecho natural y la Filosofía del Derecho: "Derecho natural y Positivismo jurídico", "Poder y Derecho" y "Ley y Conciencia", fueron traducidos al español por aquél compañados de un estudio preliminar, publicados por la Universidad Nacional de Córdoba en 1962.

7 A cargo de Carlos Fontán Balestra y Eduardo Friker, publicada por Depalma de Buenos Aires.

8 Realizada por Juan Bustos Ramírez y Sergio Yánez Pérez publicada por la Editorial Jurídica de Chile, Santiago de Chile.

9 Véase Hirsch: "Zum 100. Geburtstag", en ZStW 116, pp. 1 y ss. especialmente $\mathrm{N}^{\circ} 5$. 
internacionalmente durante esa época. Completa, así, más de un centenar de publicaciones dedicadas a la Filosofía del Derecho y al Derecho Penal -una compilación parcial de los cuales aparece en 1975, encabezada por tres trabajos claves para entender su obra: Derecho Penal y Filosofía (1930), Causalidad y Acción (1931) y Sobre los valores en Derecho Penal $(1933)^{10}-$, reseñas y comentarios a la jurisprudencia, etc. traducidos -lo mismo que sus libros- a diversos idiomas (español, griego, italiano, coreano, francés, portugués y japonés), con lo cual su doctrina finalista se expande por los diversos continentes. Su extendida fama lo lleva a trasladarse a diversos países donde pronuncia conferencias, recibe homenajes y doctorados honoris causa, tal y como sucede en Toulouse, Tesalonia, Tokio, Seúl y Madrid, entre otras; significativa, desde luego, fue su primera visita a España el 22 de abril de 1968, donde lo recibe su más excelso y querido discípulo y traductor de aquella nacionalidad, el profesor José Cerezo Mir quien, a pedido del maestro, leyó al auditorio su conferencia "La doctrina de la acción finalista, hoy".

De igual forma, debe decirse que -además de su gran producción científica- Welzel se preocupó por difundir sus valiosos conocimientos filosóficos y jurídico penales entre sus alumnos alemanes: con él se habilitaron Stratenwerth y Armin Kaufmann ya mencionados; también: Geilen, Hirsch, Schreiber, Jakobs y Loos ${ }^{11}$. En Bonn recibió a penalistas de diversos continentes y lenguas, destacándose entre Ios hispanoparlantes J. Cerezo Mir, E. Bacigalupo, G. Romero, L. H. Schriffrin, J. B. Maier, R. Bergalli, J. Bustos Ramírez, M. Moreno Hernández -cuya tesis doctoral fue dirigida por Armin Kaufmann- $y$ N. Agudelo Betancur, entre muchos otros.

Finalmente, debe decirse que fue un escritor muy polémico y combativo y que siempre estuvo listo

\footnotetext{
10 Véase Abhandlungen, pp. 1 y ss., 7 y ss., 23 y ss.; los dos primeros en Estudios de Derecho penal, pp. 121 y ss., 147 y ss.

11 Véase Hirsch: "Zum 100. Geburstag", pp. 1 y ss.
}

a enfrentar las críticas y a corregir los desaciertos que se le mostraban, como lo evidencian las rectificaciones que hizo de su concepción; como profesor no fue un expositor elocuente, al estilo de los maestros latinos, aunque era muy sólido académicamente ${ }^{12}$.

\section{Premisas fundamentales de su pensamiento}

A grandes rasgos, pueden señalarse las siguientes notas para caracterizar las ideas y la obra del autor:

1. La superación de la antítesis entre Derecho Natural Ideal y Derecho Natural Existencial

La construcción filosófica del autor parte del presupuesto de que a lo largo de los últimos 2.500 años de evolución del pensamiento humano, dos sistemas de Derecho Natural esencialmente distintos y que sostienen concepciones fundamentalmente opuestas, han tratado de precisar la naturaleza del hombre y desentrañar el problema de la justicia: el existencial y el ideal. En efecto, el primero enseña que el ser humano se encuentra determinado por actos volitivos o impulsos de naturaleza prerracional, con lo cual se basa en decisiones condicionadas por la situación concreta dada, esto es, por la afirmación vital de la existencia; por su parte, el segundo determina la esencia del hombre a partir de la razón, por lo cual el Derecho Natural se debe concebir como un orden ideal, eternamente válido y cognoscible por la razón. Así lo plantea el agudo iusfilósofo:

12 Véase Cerezo Mir: "No era el prototipo de profesor latino de gran elocuencia, sino que las clases las daba leyendo sus notas. Pero tenía las clases muy preparadas, muy elaboradas, muy profundas. Por otra parte, era una persona muy accesible. Sin embargo, la imagen que mucha gente tiene de él es la de que probablemente sería una persona poco tolerante científicamente, debido a los muchos escritos polémicos que publicó" (Véase Barquín Sanz: "Conversaciones", en RECPC 03-C3-2001, p. 3, en www.criminet.ugr.es/recpc). 
A través de todos los tiempos y de todas las épocas en las que se acostumbra dividir la doctrina del Derecho Natural, corre una antítesis de principio, la cual, aunque oculta a veces, aparentemente por compromisos, se abre paso una $y$ otra vez con igual radicalidad. Es una antítesis que yo designaría como la antítesis entre un Derecho Natural "ideal" y un Derecho Natural "existencial" [...] Para el Derecho Natural ideal, la esencia del hombre se determina partiendo de la razón, del logos; el hombre es un ser racional y social, un anima rationale et sociale. Para el Derecho existencial, en cambio, el hombre no es primariamente un ser racional, sino que se encuentra determinado por actos volitivos o impulsos de naturaleza prerracional. Para la doctrina ideal del Derecho Natural, este es un orden ideal, eternamente válido y cognoscible por la razón; para la doctrina existencial del Derecho Natural, en cambio, este se basa en decisiones condicionadas por la situación concreta dada o en la afirmación vital de la existencia ${ }^{13}$.

Obviamente, enfrente a este dualismo gnoseológico, Welzel planteará un Derecho Natural existencial con base en el cual aspira a sentar los mojones de las construcciones de la Filosofía del Derecho de su época recogiendo, de esta manera, el fruto de ese largo debate en el mundo de las ideas.

\section{El fracaso del positivismo}

Tras la hecatombe propiciada por el Nacionalsocialismo, Welzel advierte que entre 1933 y 1945 se ha producido una cisura profunda para la teoría jurídica con el consiguiente fracaso del Positivis$\mathrm{mo}^{14}$, gestado a partir de la filosofía neokantiana del Derecho: "el formalismo y el historicismo de la filosofía del Derecho neokantiana se habían mostrado incapaces de impedir o de superar la reducción del Derecho al poder, que era la con-

\footnotetext{
13 Véase Introducción a la Filosofía del Derecho, p. 5.

14 Véase "El problema de la validez del Derecho", en Derecho injusto y Derecho nulo, pp. 73 y ss.
}

secuencia necesaria del positivismo y de la teoría de las ideologías"15. El positivismo, añade:

ha destruido la razón -que era para Kant "la facultad de las ideas"- haciendo de ella un entendimiento técnico e instrumental. Para el Derecho, ello significa su entrega total al poder establecido. Derecho es lo que está determinado por la autoridad competente; el poder soberano puede imponer todo contenido jurídico, incluso el absolutamente inmoral ${ }^{16}$.

Por eso, rechaza la contraposición entre el Derecho Natural y el positivismo jurídico y plantea la necesidad de superar, en plena posguerra, ambas posturas tratando de recoger el saldo utilizable de cada una de ellas. El jurista, pues, no puede quedarse en el mundo conceptual del positivismo sino que tiene que buscar ideas trascendentes que le confieran seguridad y universalidad a sus afirmaciones, cosa que no le proporciona el Derecho Natural.

De ahí la necesidad de desembocar, a partir de los aportes de Thomas Hobbes -quien es el primero en llevar a cabo la fundamentación jusnaturalista del derecho positivo, al señalar como nota fundamental de éste el carácter de poder conformador de la realidad- y Duns Scoto ${ }^{17}$-con su idea de consonancia de los principios de la ley natural con la primera tabla del Decálogo- en un Derecho Natural existencial, que posibilite entender el Derecho como una ordenación social de lo humano, para buscar en ambos elementos: la ordenación y lo humano, aquello que le da a aquel su nota de permanencia; por ello, puede concluir:

Lo que queda del mundo de ideas del Derecho Natural no es un sistema de principios jurídicos materiales eternos, sino la exigencia frente al Derecho positivo - una exigencia que hay que cumplir

Véase Introducción a la filosofía del Derecho, p. 230. Ibíd, p. 259.

Véase la exposición crítica que hace de ambas doctrinas, en Introducción a la filosofía del Derecho, pp. 65 y ss., 116 y ss. 
bajo condiciones siempre nuevas- de que la lucha en torno a la conformación justa de las relaciones sociales sea siempre una polémica entre ideas, $y$ no se trate de poner fin a ella por el sometimiento, ni mucho menos por la aniquilación del hombre por el hombre ${ }^{18}$.

\section{El Derecho y el poder}

De igual forma, afirma, para que un orden social se convierta en Derecho debe ser algo más que poder, esto es, ha de buscar hacer realidad lo justo y lo adecuado bajo las condiciones y supuestos de un momento histórico determinado; es, pues, ésta la única manera como el orden social se puede enfrentar con el individuo, no sólo mediante la coacción sino con la pretensión de obligarle en conciencia, contentándose con un "mínimo ético". Dicho de otra manera: el Derecho tiene que limitarse a los rasgos fundamentales de las instituciones sociales, lo cual posibilita a los que sostienen otras convicciones hacer valer su propia manera de pensar; más allá de ello, no puede pretender imponer mediante el empleo de la sanción una determinada concepción del mundo, so pena de entrar en conflicto con la conciencia del individuo ${ }^{19}$, de donde se colige que el Derecho "no puede entregar su vigencia a la aprobación en conciencia de su contenido por los individuos singulares", no empecé lo cual "en la regulación de las consecuencias jurídicas deberá respetar la sinceridad de las decisiones según criterios distintos"20.

\section{La tarea de la ciencia del Derecho}

Como quiera que rechaza la existencia de valores universales independientes de toda condiciona-

\footnotetext{
18 Ibíd., p. 267; "Verdad y límites" en Revista Jurídica Veracruzana, p. 23.

19 Véase "Gesetz und Gewissen" en Abhandlungen, pp. 313 y 314.

20 Introducción, pp. 266 y 267.
}

lidad histórica y asume que el Derecho positivo está sujeto a limitaciones intrínsecas, postula que la tarea de la ciencia del Derecho ${ }^{21}$ es elaborar las estructuras lógico-objetivas ${ }^{22}$, pues ella no está obligada a aceptar cualquier orden jurídico ${ }^{23}$. Esas estructuras ontológicas le han sido dadas de antemano al legislador y le demarcan los límites de su actividad creadora: son objetivas, porque una vez que han sido conocidas existen independientemente de que sean aceptadas o rechazadas con posterioridad; y son lógicas, pues su inobservancia trae aparejada contradicción interna y falta de unidad del orden jurídico ${ }^{24}$. Así sucede, a título de ejemplo, con los conceptos de acción final -que él retoma de Aristóteles ${ }^{25}-\mathrm{y}$ de culpabilidad como juicio de reproche, en el ámbito del Derecho Penal ${ }^{26}$.

De esta manera, la tarea de la ciencia del Derecho es elaborar en la materia jurídica esas estructuras, con lo cual ella puede cumplir una función de control y de crítica del derecho positivo; por ello, refiriéndose al Derecho Penal, dice: "el legislador no es en manera alguna omnipotente, y que está ligado a determinados límites dados en la materia del derecho. Encontrar estos límites es la misión de una tarea científica del Derecho Penal"27.

21 Obviamente, Welzel se refiere a la Dogmática Jurídica que: "aísla los principios jurídicos implícitos en un orden jurídico, expone los diversos preceptos jurídicos como componentes o consecuencias de estos principios, y permite así entender el orden jurídico o sus partes como una estructura de sentido de carácter concreto con una determinada pretensión de verdad. El método de la dogmática jurídica no es el de la explicación causal, sino el de la comprensión de sentido, ya que sólo as puede ser entendida una estructura de sentido como lo es un sistema jurídico" (Véase Introducción, p. 193).

22 También, se puede habla de estructuras lógico-concretas para referirse a la expresión alemana sachlogische Strukturen. Véase Cerezo Mir: "La naturaleza de las cosas", p. 51, nota 41.

23 Véase Welzel: "Lo permanente y lo transitorio", p. 206.

24 Véase "Naturrecht und Rechtspositivismus", en Abhandlungen zum Strafrecht, pp. 283 y 284.

25 Véase "Prólogo" a Derecho Penal. Parte general, 1956, p. IX

26 Véase Cerezo Mir: "La naturaleza de las cosas...", en Temas fundamentales, t. I, pp. 49-50.

27 Véase "Prólogo" a Derecho Penal. Parte general, 1956, p. VIII. 
Con ello se arriba, entonces, a la piedra angular de su construcción en el campo de la Filosofía del Derecho, en la que se ha visto -con razón- una apelación a la naturaleza de la cosa -o sea, la vinculación del Derecho a la realidad, objeto de su regulación ${ }^{28}$ - como materia de algunas construcciones de la posguerra, ${ }^{29}$ problema este bastante antiguo dado que ya aparece en el pensamiento griego y perdura en el mundo romano ${ }^{30}$.

Por supuesto, esta perspectiva metodológica de análisis resulta innovadora si se tiene en cuenta que le da al Derecho Penal un necesario toque realista que contrasta, frontalmente, con el punto de partida de la construcción neokantiana ${ }^{31}$.

\section{La autonomía ética del ser humano como postulado fundante}

Asimismo, dirá que la autonomía ética del ser humano es el principio límite de cualquier construcción jurídica y, por tanto, del Derecho Penal ${ }^{32}$, pues no basta con unas estructuras lógico objetivas u ontológicas para poder controlar el poder punitivo del Estado, sino que, también -para lo cual parte de los datos de la antropología moderna- es necesario acudir a la existencia de principios materiales inmanentes, universalmente válidos y permanentes, que no puedan ser desconocidos. En palabras suyas:

Obviamente, que el derecho esté ligado a la realidad no significa que esté atado a las estructuras lógico-objetivas; como advierte Cerezo Mir: "lo ontológico es lo referente al conocimiento del ser y que no puede confundirse con lo fáctico o lo real. Los entes pueden ser reales o ideales. La consideración por parte del Derecho de la realidad, objeto de su regulación, no implica, por sí misma, la vinculación del mismo a estructuras lógico objetivas" (Véase "Ontologismo y normativismo en el Finalismo", p. 46).

29 Sobre ello, Tjong: "Origen y fundamento de la teoría de las estructuras lógico-objetivas" en Doctrina Jurídica, pp. 2 y ss.; Moreno Hernández: Die finale Handlungsbegriff, pp. 175 y ss.; Zaffaroni: Tratado, tomo II, pp. 298 a 305.

30 Véase Cerezo Mir: "La naturaleza de las cosas...", en Temas fundamentales, t. I, p. 40

31 Zaffaroni: " $¿ Q$ Qué queda del finalismo en Latinoamérica", p. 115; Schünemann: "La relación entre ontologismo y normativismo", en Modernas tendencias, p. 660.

32 Véase "Naturrecht und Rechtspositivismus", en Abhandlungen zum Strafrecht, pp. 286 y 287. el reconocimiento del hombre como persona responsable (más exactamente, como persona destinada a ser responsable por sí misma) es el presupuesto mínimo de un orden jurídico, esto es, de un orden social de mando que no solo pretende imponerse por medio de la fuerza triunfante, sino que quiere también obligar como un orden de deber $\operatorname{ser}^{33}$.

Lo anterior es producto de que, con su punto de partida, el Derecho no es sólo un poder que ayuda a configurar la realidad sino que también lleva implícito un momento valorativo que está dado por la autonomía ética, la única que posibilita al hombre mantenerse a lo largo del tiempo como sujeto idéntico en todas las transformaciones históricas. Dicho de otra forma: sin la nota de positividad, el Derecho se torna en una simple abstracción o en la aspiración ideal de un orden posible; $y$, sin su nota axiológica fundamental, se vuelve mero ejercicio de la fuerza incapaz de cumplir con el axioma fundamental de todo ordenamiento: el respeto de la autonomía ética del ser humano. Por ello, el Derecho sólo puede obligar al hombre en tanto que lo conciba como persona, si no lo hace deviene en simple poder $y$, por tanto, en terror estatal ${ }^{34}$.

33 Véase "El problema de la validez del Derecho", en Derecho injusto y Derecho nulo, p. 109; "Verdad y límites" en Revista Jurídica Veracruzana, pp. 9-10. El mismo: "El reconocimiento de hombre como persona responsable es el presupuesto mínimo que tiene que mostrar un orden social si este no quiere forza simplemente por su poder, sino obligar en tanto que Derecho" (Introducción a la Filosofía del Derecho, p. 252).

34 Véase "Naturrecht und Rechtspositivismus", en Abhandlungen zum Strafrecht, p. 287; "Macht und Recht”, en la misma obra, p. 296. Muy bien dice Recasens Siches: "El Derecho también puede obligar al hombre sólo en tanto persona. Pero entonces tiene a su vez que reconocerlo como persona. El Derecho, en tanto que es orden normativo, presupone como propia condición de posibilidad, el reconocimiento tácitamente presupuesto del hombre como persona. En el reconocimiento tácitamente presupuesto del hombre como persona reside la diferencia decisiva entre el Derecho y el simple poder, y no en una característica formal y peculiar del ejercicio del poder, como es la regularidad. La durabilidad del simple terror es imposible. El hombre está construido de tal manera que no puede existir cuando continuamente es utilizado como ciego instrumento sin responsabilidad personal" (Panorama, tomo II, p. 934). 


\section{La lucha por la Democracia}

También, de manera insistente, reclama que las organizaciones políticas civilizadas se configuren como verdaderos Estados de Derecho democráticos y participativos, bajo cuya égida se tornen posibles el libre debate de las ideas, la tolerancia recíproca, la libertad y la construcción de sociedades abiertas, en lo que ve el legado más importante del Derecho Natural. En efecto, dice:

La idea fundamental de la democracia es, por ello, el aseguramiento de la disposición fundamental de todos los grupos en lucha por el poder político, a que la lucha por el orden social justo sea llevada a cabo como una lucha de ideas, sin tratar de aniquilar como enemigo al que piensa de otra manera, tan pronto se han conseguido la mayoría y el poder. En la democracia, todo el mundo tiene el derecho a expresar su opinión, siempre que el mismo esté dispuesto también a escuchar la opinión contraria. La democracia descansa en la idea fundamental de la tolerancia recíproca, no de la tolerancia irracional, y el mismo principio de la mayoría está subordinado a aquella idea. En este sentido, la democracia es una societé ouverte. Uno de los elementos integrantes es el aseguramiento de la libertad frente a aquellos grupos que pretenden utilizar la tolerancia para aniquilar la libertad ${ }^{35}$.

De otra forma dicho: hay en el profesor alemán una profunda preocupación por la libertad y es innegable que su concepción ha hecho un importante aporte a la Teoría de la Democracia ${ }^{36}$.

35 Véase Introducción, pp. 264 y 267; “Verdad y límites” en Revista Jurídica Veracruzana, p. 20. El mismo ("El problema de la validez del Derecho", en Derecho injusto, p. 112), señala: "El proceso de formación de la voluntad estatal tiene que estar bajo el principio de la tolerancia mutua; el Derecho tiene que limitarse al "mínimo ético" y a los rasgos fundamentales de las instituciones sociales; en los tipos de consecuencias jurídicas es preciso tener en cuenta la fidelidad a la conciencia de cualquier dictamen serio de ésta que sea discordante, etc. La lucha, que no acabará nunca en la historia humana, por lograr la configuración justa de las relaciones sociales tiene que ser llevada y mantenida por el Derecho positivo en un terreno que permita la discusión espiritual y no liquidarla con el sometimiento forzoso o incluso la aniquilación de los hombres por otros hombres".

36 Véase Hirsch : "Zum 100. Geburtstag von Hans Welzel" en ZStW $116,2.004$, cuaderno 1, pp. 10 y ss.

\section{Las normas jurídicas sólo se refieren a actos}

Como consecuencia lógica de su punto de partida filosófico, dice que -atendida la estructura lógico-objetiva de la acción humana- las normas jurídicas y morales sólo se dirigen a actos que son algo distinto a meros procesos causales, de los cuales se distinguen por el momento de la dirección consciente hacia un objetivo, esto es, por la idea de finalidad. Ello es fruto de que las llamadas "estructuras de sentido" tienen fronteras inmanentes derivadas no sólo del carácter de la llamada del deber ser, sino de las propias estructuras ónticas que se deben interpretar, pues "las constelaciones objetivas ónticas son preliminares a toda interpretación de su sentido, y estas se hallan, por eso, vinculadas a aquellas". Por ello, afirma:

ninguna norma, ni moral ni jurídica, puede preceptuar a las mujeres que den a luz hijos viables a los seis meses, en lugar de a los nueve, como no pueden tampoco prohibir a un aviador que si se precipita contra el suelo, no traspase la velocidad de treinta kilómetros por hora. Estas y otras proposiciones semejantes son la consecuencia trivial de la idea nada trivial de que todas las normas morales y jurídicas sólo pueden referirse a actos, los cuales son algo distinto de meros procesos naturales causales, distinguiéndose de estos por el momento de la dirección consciente hacia un objetivo; es decir, por el momento de la "finalidad". La estructura de la acción humana es el presupuesto de posibilidad para valoraciones, las cuales, si han de tener sentido, sólo pueden ser valoraciones de una acción, tales como, p. ej., la ilicitud y la culpa. En el campo de la llamada doctrina de la imputación o de la acción es, por eso, también donde la doctrina del Derecho Natural ha realizado progresos más firmes desde Aristóteles y los escolásticos ${ }^{37}$.

\footnotetext{
37 Véase Introducción, pp. 256 y 257; el mismo: "Prólogo" a El nuevo sistema, pp. 31 y 32.
} 
Desde luego, ello lo lleva a abogar por un Derecho Penal de acto, como claramente lo propone en sus trabajos dedicados a esta materia ${ }^{38}$.

8. Una sistemática del delito subjetivoobjetiva, en contraposición a la Causalista

A tono con lo anterior, el expositor pone en escena todos y cada uno de sus planteamientos en el ámbito del Derecho Penal, dando lugar a una construcción del delito que revolucionó toda la dogmática de su época -asentada sobre el dogma causal-, el finalismo ${ }^{39}$, que ha tenido una influencia muy marcada durante los últimos cincuenta años no sólo en su patria sino fuera de ella ${ }^{40}$; obviamente, el punto de partida de esta transformación dogmática finca en la estructura fundamental de la acción (y con ella el concepto personal del injusto) y los principios de culpabilidad que "conforman los dos puntos sólidos que, desde 'fuera' -es decir, a partir de la constitución fundamental del hombre como un ser activo y obligado a un sentido de la vida que se manifieste en sus acciones-, se extiende al Derecho Penal y entre los cuales se mueve la verdad histórica de las regulaciones jurídico penales" ${ }^{\prime 41}$.

38 Véase "Prólogo" a Derecho Penal. Parte general, 1956, p. VIII: "Las normas del derecho penal, vale decir, sus imposiciones y prohibiciones, pueden dirigirse únicamente a acciones humanas. Ningún derecho puede imponer o prohibir algo a meros procesos de la naturaleza. Sólo en cuanto alcancen el poder finalista de creación de las acciones humanas sobre los acontecimientos de la naturaleza, el derecho puede imponer o prohibir algo a las acciones".

39 Véase Cerezo Mir: "El Finalismo, hoy", en Temas fundamentales,

t. I, pp. $381 \mathrm{ss}$.

40 Para entender el origen y evolución de la sistemática finalista y, por ende, de la ciencia penal alemana, es de vital importancia Welzel: "Die deutsche Dogmatik", en JS, t.11, 1966, pp. 421 y ss., que recoge conferencia dictada por él en las Universidades de Nihon en Tokio (Japón) y Kjung-Hi de Seul (Corea) a comienzos de 1966. También: Busch: Modernas transformaciones, pp. 11 y ss.

41 Así Welzel: Abhandlungen, p. 365. Naturalmente, las bases se sentaron ya en 1930, 1931 y 1933 en los tres artículos ya citados; pero, sobre todo, en sus trabajos de 1935 (Naturalismo y Filosofía del Valor) y 1939 (Estudios sobre el sistema del Derecho Penal).

\section{APROXIMACIÓN CRÍTICA}

\section{Algunos cuestionamientos}

La vida y la obra de Welzel han sido objeto de no pocos ataques que van desde lo político, pasando por su concepción filosófica y llegando hasta lo estrictamente sistemático en el ámbito del Derecho Penal. Centrando la atención en el primero de estos aspectos se observan tres posturas diferentes $^{42}$ : una de carácter radical, encabezada por T. Würtenberger, según la cual sus construcciones tienen innegables coincidencias con el Derecho Penal totalitario ${ }^{43}$; en esta misma línea de reflexión K. Marxen, en su conocido escrito de Disertación, no duda en calificar a Welzel como uno de los teóricos que -al lado de G. Dahm y F. Schaffstein- abanderó la lucha contra el Derecho Penal liberal ${ }^{44}$. Es más, este autor asegura que la dura crítica de Welzel al Naturalismo y a la Filosofía de los valores, así como sus manifestaciones en el ámbito del Derecho Penal, posibilitaron la apertura hacia el Nacionalsocialismo; incluso, cita párrafos textuales extraídos del trabajo de habilitación del citado profesor que, según él, "se corresponden directamente con el ideario nacionalsocialista" ${ }^{45}$.

También, I. Müller dice que fue un auténtico ideólogo del régimen nazi ${ }^{46}$, mientras que el chileno S. Politoff asevera que "ha prestado, antes y después de 1945, una importante contribución

42 Sobre estas tres posturas Llobet Rodríguez: "Prólogo" en Borja Jiménez: Ensayos, pp. 11 y ss.

43 Véase Würtenberger: La situazione spirituale, pp. 84 y ss.

44 Véase Marxen: Der Kampf, pp. 20 y ss.; 71 y ss.; 197 y ss.; 217 y ss. No obstante, Vives Antón: Fundamentos, p. 24, alude a "las $\square$ discutibles $\square$ implicaciones totalitarias del finalismo".

45 Véase Marxen, Klaus: Der Kampf, pp. 41 y 42, nota 135. En contra, pues, de lo algunos niegan o no quieren discutir -Véase Hirsch: "Zum 100. Geburstag", pp. 1 y ss., especialmente lo dicho en el No 5- Welzel no era ajeno a ideas como la "pureza de la sangre" y "de la raza alemana", "la voluntad del Führer" plasmada en la Ley y "la comunidad del Pueblo" como valores concretos de la cultura y no los valores abstractos y metafísicos de los neokantianos, que él combatía. Véase Abhandlungen, pp. 86 y 105.

46 Así Müller: Furchtbare Juristen, pp. 223 y 224. 
al autoritarismo y al modelo amigo-enemigo al trasladar el centro de gravedad del Derecho Penal a la 'comprobación de un ánimo conforme al Derecho'" ${ }^{\prime 47}$. No muy lejos de esta línea de análisis se encuentra L. Ferrajoli quien, después de mostrar cómo la postura del pensador germano aparece a caballo entre las sugerencias neokantianas y de la Filosofía de los valores -para las cuales la acción era un acto "dotado de significación social"- y el entendimiento de la acción como un simple síntoma de la personalidad del delincuente con los penalistas de la llamada Escuela de Kiel-, lo acusa de haber ayudado a sentar-con su concepto final de acción y con su teoría del ilícito personal ${ }^{48}$ - las bases para la progresiva subjetivización del concepto de acción que, según él, "disuelven el elemento objetivo en el disvalor, inicialmente, de la acción y después de la voluntad, dentro de un contexto de subjetivización integral del Derecho Penal como instrumento de simple represión de la subjetividad desleal" ${ }^{\prime 9}$.

De otro lado, siguiendo una línea de pensamiento menos radical, $M$. Frommel asevera que la Teoría final de la acción tiene claros orígenes ideológicos, dado que en sus inicios "tuvo una función legitimadora" del statu quo, por lo cual la califica como una respuesta conservadora enfrente al régimen nacionalsocialista, a cuyo efecto se basa en sus trabajos Culpabilidad y personalidad (1939) y Sobre el concepto sustancial de Derecho Penal de los cuales, dice, se desprende una construcción

47 Así Politoff: "Sistema jurídico-penal y legitimación" en NFP $N^{\circ} 45$, p. 318, Ilamándolo "ideólogo del régimen"; el mismo: "Adecuación Social y terror en América...", en DPC № 22, pp. 73 y ss.

48 Para una exposición crítica sobre la doctrina del "ilícito personal”, véase a Würtenberger: La situazione spirituale, pp. 73 y ss.

49 Véase Derecho y razón, pp. 486, 496, 514 (nota 42), 521 (nota 92) y 530 (nota 131), se apoya el conocido iusfilósofo italiano en la traducción italiana del escrito de Würtenberger: La situazione spirituale, pp. 74 y ss. del "tipo normativo de autor" propia del régimen de la época ${ }^{50}$. En fin, un expositor tan calificado y polémico como F. Muñoz Conde, apoyado en la citada expositora, advierte que para esa época Welzel era "un joven docente lleno de ambiciones" que entonces no tenía mucha importancia para el régimen ${ }^{51}$, con lo cual parece no darles tanta trascendencia a las críticas más radicales.

Finalmente, los defensores más serios y fervientes del festejado pensador plantean, por boca de Hirsch, que el maestro no asumió ninguna participación en el régimen nazi y que, así como millones de alemanes, no tuvo más opción que vivir en aquella época para no perder su puesto de trabajo y sostener a sus numerosos hijos. Incluso, aducen como pruebas de ello el hecho de que, después de la guerra, fue elegido como el primer decano de la Facultad de Derecho de la Universidad de Göttingen y que, además, obtuvo un dictamen favorable sobre su vida y su obra en 1947, al cual ya se hizo referencia ${ }^{52}$. Por supuesto, para que no se crea que esta es una opinión solitaria, es bueno rememorar que E. Schmidt, en su texto dedicado a la historia de la administración de justicia penal en Alemania, no hace ninguna alusión negativa al profesor de Bonn cuando expone el periodo se-

50 Así Frommel: "Los orígenes ideológicos", en ADPCP 1989, pp. 621 y ss. Por ello, escribe: "Después de todo esto más de uno se preguntará cómo pudo alcanzar la teoría final de la acción tanta importancia a partir de 1945; una teoría que originalmente tuvo una función legitimadora, pero que, en su construcción, llegó demasiado tarde y respondía a una concepción filosófica "anticuada"" (p. 629); y: "...Vistas así las cosas, el "Derecho penal de voluntad" y la fundamentación filosófico-valorativa que Welzel propugnaba en 1935, no eran más que la última consecuencia de un clima politicocriminal que reclamaba "mayor dureza, ignorando las consecuencias que estas posturas podían tener"” (p. 631). Como ella Llobet Rodríguez: "Prólogo" en Borja Jiménez: Ensayos, pp. 11 y 12.

51 Véase: Muñoz Conde: Edmund Mezger y el Derecho penal, pp. 85 y ss., especialmente nota 27, apoyado en Frommel, aunque no deja de reconocer que Welzel tuvo "cierta relevancia" en la época nacionalsocialista (Véase p. 122, nota 73); Borja Jiménez: Ensayos, p. 101, no sin advertir que "no ha quedado todavía claro cual pudo ser la implicación del prestigioso jurista en este régimen del terror".

52 Así Hirsch: "Zum 100. Geburtstag", en ZStW 116, pp. 1 y ss. especialmente $\mathrm{N}^{\circ} 5$. 
ñalado, limitándose únicamente a mencionar que en su trabajo pionero de 1935, confrontó su teoría de la acción final con las concepciones causales hasta entonces vigentes ${ }^{53}$.

También, situados ya en un plano estrictamente académico, debe decirse que la Teoría Final de la acción desató una intensa polémica ${ }^{54}$ y posibilitó muchas críticas de orden sistemático, sobre las que no es del caso entrar aquí en mayores disquisiciones $^{55}$. Sin embargo, es bueno recordar como, en materia de delitos imprudentes -uno de los tópicos más debatidos y sobre los que el fundador del finalismo se vio obligado a hacer diversas rectificaciones- él mismo se ocupó de combatir a sus críticos al punto de que, en la Relación presentada al VIII Congreso de la Asociación Internacional de Derecho Penal, en Lisboa (1961), expuso una versión bastante acabada de su construcción ${ }^{56}$.

53 Véase Schmidt: Einführung, p. 429. Es sintomático, por lo demás, que este expositor no aluda a sus demás artículos y libros de la época.

54 Algunos, incluso, dicen que el sistema de Welzel no es "finalista" sino "finista". Véase Fernández Carrasquilla: Derecho penal, Vol. 1, p. 287: "Seguimos hoy sosteniendo que este "finalismo" de Welzel es en realidad de verdad un "finismo"; en otras palabras, el sistema welzeliano no se determina por la categoría ontológica de la finalidad, de suyo pluridimensional como todo lo humano, sino por la categoría sicologista del "fin" (contenido síquico del acto volitivo), que poco toma en consideración el sentido social de la acción, su inordinación dentro de un conjunto axiológico supra-individual y supra-sicológico que no es un "también" (algo que se agrega afuera), sino un "en sí"".

55 Pueden verse, entre muchos otros: En Alemania: Jakobs: Derecho penal, prólogo a la primera edición y pp. 162 y ss.; Roxin: "Contribución a la crítica de la teoría final de la acción", en Problemas básicos, pp. 84 y ss. En España: J. A. Rodríguez Muñoz: La Doctrina de la acción finalista, pp. 83 y ss., con una presentación de las críticas alemanas de la época; J. Córdoba Roda: Una nueva concepción, pp. 57 y ss.; Suárez Montes: Consideraciones críticas, pp. 11 y ss.; S. Mir Puig: Introducción, pp. 245 y ss.; E. Gimbernat Ordeig: ¿Tiene futuro la Dogmática Penal?, pp. 58 y ss.; Silva Sánchez: Aproximación, p. 57 y ss. Para Chile: Novoa Monreal: Causalismo y Finalismo, pp. 41 y ss., 181 y ss., con brillante réplica de E. R. Zaffaroni (pp. 137 y ss.). En Italia: Marinucci: El delito como "acción”, pp. 57 y ss. En Colombia: Fernández Carrasquilla: Derecho penal, Vol. 1, pp. 268 y ss., especialmente, 350 y ss.

56 Véase H. Welzel: "La imprudencia y los delitos de la circulación", en Cuadernos de los Institutos, No 84, pp. 113 y ss. ; previo a este trabajo es importante: “Die finale Handlungslehre", en JZ No 10-11, en donde afirma que es posible hacer una construcción del delito imprudente a lo largo de las categorías del delito, al estilo de lo que sucede con los delitos dolosos (Véase p. 317). También: Um die finale Handlungslehre, pp. 3 y ss., 17 y ss.
También, en 1964, el propio Welzel -en alusión a Roxin $^{57}$, que en 1962 había publicado un trabajo profundamente cuestionador-, dijo que se le habían hecho reproches infundados no exentos de contradicciones e incluso con citas de segunda mano, los cuales enfrentó con profunda claridad e inteligencia respondiendo de manera puntual a cada uno de ellos ${ }^{58}$, sin que -cuarenta y cinco años después- el jubilado profesor de München haya ofrecido una respuesta satisfactoria y totalmente convincente ${ }^{59}$. Asimismo, en 1968, luego de que H. Mayer publicara su "Manual", también Welzel le replicó dura y contundentemente, cuestionando de paso a E. Gimbernat Ordeig, por tergiversar los alcances de Teoría Final de la acción ${ }^{60}$.

\section{Valoración de las críticas}

Por supuesto, sin entrar en polémicas estériles y con miras a evaluar las censuras que se le han hecho a tan insigne académico desde una perspectiva política, es irrefutable que el trabajo con el cual Welzel se habilitó como catedrático en 1935 -"Naturalismo y Filosofía de los valores", recuérdese-, fue muy bien recibido por algunos de los partidarios del Derecho Penal autoritario de entonces ${ }^{61}$; es más, en él saludó con beneplácito el advenimiento del régimen entonces imperante, cuando se refirió a "la revolución espiritual de

57 Véase Roxin: "Contribución a la crítica de la teoría final de la acción", en Problemas básicos, pp. 84 y ss.; con más mesura, Schünemann: El sistema, pp. 58 y ss.

58 Véase Abhandlungen Ob. cit., p. 345 y ss., con traducción de Moreno Hernández: "Lo permanente y lo transitorio", Ob. cit., pp. 203 y ss.

59 También, otros continuadores de la obra de Welzel han respondido a los opositores: Hirsch: Obras completas, tomo I, pp. 13 y ss.; Cerezo Mir: Temas fundamentales, tomo I, pp. 381 y ss.; "Ontologismo y normativismo en el Finalismo", pp. 45 y ss.; Moreno Hernández en Modernas Tendencias, pp. 579 y ss.; Zaffaroni, en Novoa Monreal: Causalismo y Finalismo, pp. 137 y ss., entre muchos otros.

60 Véase Welzel: "Ein unausrottbares mi[verständnis?", en NJ, pp. 425 y ss.; este trabajo le sirvió a Welzel para confeccionar su muy sonada conferencia en Madrid, en 1968: Véase "La doctrina de la acción finalista, hoy", en NFP № 1, pp. 60 y ss.

61 Véase Las referencias de Frommel: "Los orígenes ideológicos", p. 628. 
1933" que, en su sentir, tenía gran significación "para nuestra ciencia"62, como parte de la necesaria adhesión política que tal ascenso en su vida académica implicaba.

Asimismo, como prueba de su compromiso con esa "revolución espiritual", concurrió como ponente al encuentro promovido por la "NS.-Rechtswahrerbund", los días 30 y 31 de marzo de 1937 en Eisenach -Tagung der strafrechtlichen Arbeitsgemeinschaft der Reichsfachgruppe "Hochschulleherer"-, donde disertó con profundidad sobre "el honor de la comunidad" (tanto el del Estado como el de la familia) coincidiendo, en buena medida, con los planteamientos de G. Dahm, temática de suma importancia para el Nacionalsocialismo y que él abordó, remontándose hasta la antigua filosofía griega y al Derecho romano, apoyado en Kant y Hegel, rindiendo claro tributo a las ideas de la época ${ }^{63}$.

De igual forma, recuérdese, utilizando el metalenguaje de entonces ${ }^{64}$-aunque cuidándose de exageradas y vistosas loas, muy propias de los partidarios del Derecho Penal de la voluntad-, en esa época dio a la luz las tres ediciones de su Compendio de la Parte General (Grundriss des Allgemeinen Teils), en las que utiliza la terminología de entonces; no obstante, en honor a la verdad, debe decirse que en su significativa monografía "Estudios sobre el sistema del Derecho Penal" (1939) -en la que recoge las bases sentadas en sus dos famosos artículos de 1930 y 1931, y traza el esquema de su Derecho Penal-, no se eviden-

\footnotetext{
62 "Naturalismus und Wertphilosophie im Strafrecht", en Abhandlungen zum Strafrecht, pp. 29 y ss., 118, para constatar como un Welzel pletórico de energías, saluda al régimen desde su tribuna de académico y anuncia una ciencia combatiente contra el liberalismo.

63 Véase "Über die Ehre von Gemeinschaften", en ZStW, Vol. 57, pp. 28 y ss. De especial importancia son sus planteamientos contenidos en las pp. 41 y ss.

64 Así, Llobet Rodríguez: "Justicia Penal" en el Estado arbitrario, pp. 9 y ss, especialmente la nota 2.
}

cia ninguna referencia explícita al régimen ${ }^{65}$. Sin embargo, en 1941, cuando dio a la luz su extenso y muy importante artículo intitulado "Personalidad y Culpabilidad"66 —en el cual, por lo demás, con espaciosas citas funda su concepción de la culpabilidad en Aristóteles ${ }^{67}-$, hizo alusiones expresas a los aportes que la biología, las teorías de la herencia y de las razas, la psicología y la psiquiatría de la época hacían al entendimiento del ser humano; esto es, aludía a los "descubrimientos" nacionalsocialistas en estos campos ${ }^{68}$.

Además, en 1944, no dudó en afirmar que en situaciones excepcionales como la "de guerra" - irecuérdese el momento que vivía el régimen hitleriano en ese año!- el Estado quedaba dispensado de sus últimas ataduras jurídicas, por ejemplo la de la tipicidad de las normas de Derecho Penal, para superar el peligro, todo en aras de proteger los valores predominantes: la lealtad en relación con el pueblo, el Estado, el Führer, la obediencia al poder de coacción del Estado, y la disposición de prestar servicio a las Fuerzas Armadas ${ }^{69}$.

Asimismo, para ocuparse de los aspectos dogmáticos y filosóficos, también es indudable que cuando él -sobre todo después de la guerra- hizo esfuerzos por buscar principios que sirvieran de valla o muro de contención al irracionalismo, en esencia a través de la erección de su teoría de las estructuras lógico-objetivas, necesariamente

65 Véase Abhandlungen, pp. 120 y ss.; Estudios de Derecho penal, pp. 15 y ss.

66 Véase "Persönlichkeit und Schuld" en Abhandlungen, pp. 185 y ss.

67 Véase "Persönlichkeit und Schuld" en Abhandlungen, pp. 210 y 211.

68 Véase "Persönlichkeit und Schuld" en Abhandlungen, p. 186: "Hier haben uns in der Tat die letzten Jahre zu Ergebnissen geführt, die auch strafrechtlich von entscheidender Bedeutung sind Biologie, Erb- und Rassenlehre, Psychologie und Psychiatrie haben wesentliche Bestandstücke beigetragen, die von den verschiedensten Seiten her in einem einheitlichen Bilde vom Menschen zusammenlaufen oder doch wenigstens einem solchen einheitlichen Bilde zustreben". Muy crítico, Llobet Rodríguez: Justicia Penal, p. 10, nota 2.

69 “Über den substantiellen Begriff des Strafgesetzes", en Abhandlungen zum Strafrecht, pp. 233 y ss., 239 y 240. 
desembocó en un planteamiento "metafísico" de verdades no discutibles; sus fuertes críticas al Positivismo y al teleologismo neokantiano lo llevaron, pues, al terreno del iusnaturalismo así fuera de corte existencial ${ }^{70}$.

Desde luego, debe afirmarse que su obra intitulada "Introducción a la Filosofía del Derecho" en la última versión española, es un trabajo en extremo acabado que lo coloca como uno de los adalides de la discusión filosófica durante los últimos cincuenta años. Se trata de una investigación erudita, profunda y apasionante, que -de repente-, como ha dicho uno de sus discípulos, desmonta las concepciones iusnaturalistas hasta entonces formuladas al considerar que en todas hay un círculo vicioso: incluir previamente en el concepto de naturaleza humana lo que se considera valioso y, después, deducir su carácter valioso del dato de que está presente en la naturaleza humana ${ }^{71}$.

De igual forma, también parece indiscutible que "el concepto personal de lo injusto", radicalmente planteado por él en íntima conexión con su construcción de la acción, estaba más cerca del Derecho Penal de la voluntad de la llamada Escuela de Kiel que de un Derecho Penal liberal ${ }^{72}$, porque supone una concepción voluntarista de los valores, para el cual "la voluntad ordenada" aparece "como el objeto primario de la valoración"73; afortunadamente, para el bien del Derecho Penal

Como dice Bustos Ramírez (Introducción, p. 169): "al incorporarse aunque atenuadamente a la búsqueda de principios esenciales que significaran una valla al irracionalismo, cayó necesariamente en un planteamiento "metafísico" de verdades no discutidas... El finalismo no logra, a pesar de sus críticas, superar las raíces profundas del jusnaturalismo" (p. 169).

71 Véase Cerezo Mir, en Barquín Sanz: "Conversaciones", en RECPC 03-C3-2001, p. 3, en www.criminet.ugr.es/recpc.

72 Véase Muñoz Conde: Edmund Mezger y el Derecho penal, p. 87, nota 29. Prueba de ello es que el propio Welzel así parece reconocerlo: Véase Estudios, p. 17; además, con citas concretas, muestra la aceptación que su postura ha tenido entre partidarios de la Escuela de Kiel (p. 30 nota 23); Abhandlungen, pp. 121 nota 6 y 129 nota 22. Por ello, parece equivocado afirmar que la Escuela de Kiel es un precedente del Finalismo (Véase Fernández Carrasquilla: Derecho penal, Vol. 1, p. 276). liberal, este planteamiento ha hecho poca carrera y es rechazado, casi de manera generalizada, por la dogmática contemporánea ${ }^{74}$, máxime que va de la mano de una andadura teórica para la cual la misión del Derecho Penal no es proteger bienes jurídicos sino valores ético sociales: "la misión del Derecho Penal consiste en la protección de los valores elementales de conciencia, de carácter ético-social, y sólo por inclusión la protección de los bienes jurídicos particulares" ${ }^{75}$.

Naturalmente, casi treinta años después de la muerte de este gran pensador y cuando la discusión jurídico penal ha seguido avanzando, se puede aseverar que sus trabajos no se extendieron a la teoría de la pena, con lo cual se ha quedado una muy importante elaboración sin desarrollar, cuestionamiento cierto pero que no puede llevar a reclamarle al genio de Welzel, después de una larga y difícil carrera académica, que dejara solucionados todos los problemas que sus posturas teóricas demandaban, pues -parafraseándolo-ni siquiera Atenea salió perfecta de la cabeza de su padre Zeus.

También, mirada la concepción welzeliana desde la perspectiva político-criminal, se ha dicho que ella se dejó absorber por la preocupación del sistema ${ }^{76}$, cosa de suyo evidente hoy si se piensa en las formulaciones actuales, pero incorrecta si se tiene en cuenta que desde su perspectiva él, más que nadie, abogó por una Dogmática ceñida a la realidad con lo cual no fue ajeno a las repercusiones político-criminales de su sistema ${ }^{77}$.

74 Bien diciente es al respecto la acertada crítica de Bustos Ramírez: Bases Críticas, pp. 26 y ss.

75 Véase Welzel: Derecho penal, p. 15.

76 Ya desde 1965 se le hacía esta crítica: Véase Rodríguez Mourullo: "El teleologismo valorativo", en Boletín No 73, p. 226, nota 117.

77 Así lo ha demostrado, por ejemplo, Cerezo Mir: "Ontologismo y normativismo en el Finalismo", p. 55 y ss.; Moreno Hernández: "Ontologismo o Normativismo", en Modernas tendencias, pp. 591, 592 y 608, recordando como el propio Welzel, dijo al referirse a la ciencia penal: "Como ciencia sistemática establece la base para una administración de justicia igualitaria y justa, ya que sólo la comprensión de las conexiones internas del Derecho liberan a su aplicación del acaso y la arbitrariedad" (Derecho penal alemán, p. 1). 
Por supuesto, también es claro que tras la hecatombe nazi él fue uno de los pensadores que, renovando su prédica, con vehemencia, reclamó un Derecho Penal erigido sobre el respeto de la dignidad de la persona y exigió que la ciencia Penal se tenía que constituir en un bastión para controlar el poder punitivo del Estado.

Desde luego, es sobre este Welzel y el de la preguerra - que ya en sus dos célebres artículos de 1930 y 1931 echó las bases de toda su construcción finalista ${ }^{78}$ - sobre el que se debe volver la mirada, sin caer -sobre todo en Latinoamérica- en críticas fragmentarias acompañadas muchas veces de gran contenido emotivo, pues no parece viable científicamente hablando pretender evaluar toda la obra de un pensador condicionando el análisis sólo a un determinado momento de su existencia, porque ello sería marcadamente injusto, tornándose verdad aquello de que "los árboles no dejan ver el bosque".

En otras palabras: si bien en la obra de $\mathrm{H}$. Welzel se observan referencias y adhesiones al régimen autoritario que entonces dominaba en Alemania, y es innegable que él ejerció como docente a lo largo del mismo, también resulta odioso pretender que él -a diferencia de otros importantes profesores del momento, que optaron por doblegarse ante el tirano de turno- se haya alistado en las filas nazis para servir de ideólogo. Debe, pues, evitarse la crítica irreflexiva, ligera, dañina, sin pensar que se deben rescatar los enormes logros de este pen-

78

Sin embargo, la concepción Finalista propalada por Welzel tiene ya precedentes $\llbracket$ sin olvidar a H. von Weber ("Para la estructuración del sistema" en NFP № 13, pp. 570 y ss. y "Fundamentos de Derecho penal Checoslovaco", la primera de 1935 y la segunda de 1929) y a A. Graf zu Dohna (1936: La estructura, pp. 13 y ss.), por la misma época ya hicieron importantes contribuciones a la misma en P. Merkel (P. Merkel: "Die Bestimmungen des Strafgesetzenwurfes", en ZStW, t. 43, 1922, pp. 299 y ss.) y su discípulo O. Berg, acompañados por E. Wolf (1928), quienes demostraron cómo el dolo y la culpa eran formas de conducta (Sobre ello: Achenbach: Historische, p. 184). Por ello, no es acertado afirmar que el Finalismo apenas se forja hacia 1938 (Véase Fernández Carrasquilla: Derecho penal, Vol. 1, p. 277). sador y no valorarlo sólo por sus desaciertos; él, no se olvide, logró renovar la dogmática de su tiempo tanto en sus bases filosóficas como científicas, y permitió una reestructuración más coherente de todo el sistema penal ${ }^{79}$.

En fin, a pesar de las críticas, la obra de este brillante catedrático sigue teniendo vida y es un punto obligado de referencia para la discusión; su rigor metódico, su honda formación filosófica, su capacidad crítica, su enfoque realista, etc. son alicientes para quienes, de una o de otra manera, se ocupan de estas materias; que ello es así lo corrobora el hecho de que, recientemente, se le haya dedicado en Alemania un extenso estudio monográfico a su pensamiento ${ }^{80}$.

Con razón, pues, un brillante expositor uruguayo afirma: "Poco cuenta ahora que su honda inquietud filosófica, las bases ontológicas del sistema o su connotación eticista, resulten cuestionadas -mejor aún, superadas- por las orientaciones dogmáticas de fin de siglo. Así y todo, Welzel nos enseñó a pensar y nos plantó de cara al problema central de la ciencia penal, que continúa siendo el problema del hombre" ${ }^{\prime 11}$. Y Zaffaroni, con su habitual lucidez, expresa: "el aporte de Welzel fue, precisamente, abrir la ventana del Derecho Penal, romper el candado que le vedaba la visión del mundo, aunque deslumbrado por la luz y limitado por su posición en el tiempo no sacase de eso todas las consecuencias, lo que no era humano exigirle" ${ }^{\prime 22}$.

\footnotetext{
79 Véase Bustos Ramírez: Introducción, p. 169.

80 Véase Sticht: Sachlogik als Naturrecht?, pp. 5 y ss., con recensión de Fritz Loos, en ZStW, 2002, volumen $\mathrm{N}^{\circ} 3$, pp. 674 y ss.

81 Véase Gonzalo Fernández E.:"Palabras previas" en Welzel: El nuevo sistema, pp. 15 y 16.

82 Zaffaroni: "¿Qué queda del finalismo en Latinoamérica”, p. 121.
} 


\section{CONCLUSIONES}

Luego de examinar a grandes rasgos los aportes del insigne profesor, se pueden consignar las siguientes reflexiones para la discusión.

1. Respecto a las críticas y cuestionamientos de cuño político y académico que se le han hecho a la vida y a la obra de este pensador, parece ocioso pretender negar que tuvo vínculos con el régimen político autoritario que imperó en Alemania entre 1933 y 1945; así lo prueban no sólo algunas adhesiones explícitas o implícitas existentes en sus trabajos académicos de entonces, sino su participación como conferenciante en congresos y actividades oficiales del nacionalsocialismo como el citado Congreso de Eisenach de 1937.

2. Con todo, resulta exagerado e injusto pretender valorar toda la obra académica de este estudioso a partir de los desaciertos que haya podido cometer en ese momento de su vida, pues son también innegables sus valiosos aportes en el plano político y académico después de que, tras la guerra, el mundo despertara de ese monstruoso sueño que, para mal, marcó el destino no sólo de quienes se dedicaban entonces a estas disciplinas sino del planeta entero.

3. Por ello, entonces, resulta imperioso recordar que con su peculiar punto de partida filosófico, después de la guerra Welzel denuncia -una y otra vez- los excesos del Positivismo y muestra como el Derecho no se puede confundir con el poder; asimismo, reivindica la necesidad de construir organizaciones sociales democráticas asentadas sobre el postulado de la dignidad de la persona humana, que permitan el libre debate de las ideas, luego de afirmar que la lucha por la democracia es el legado más importante del Derecho Natural, desde la antigüedad hasta hoy.

4. También, es innegable -sea cualquiera la postura que se adopte- que este expositor ha influido de manera notable y decisiva a lo largo de los últimos lustros en la Ciencia del Derecho Penal proponiendo un viraje hacia la realidad, no sólo en Alemania sino allende los océanos, todo lo cual permite catalogarlo como el más importante dogmático de los últimos cien años después de K. Binding ${ }^{83}$.

5. Asimismo, debe valorarse positivamente su gran aportación en el plano de la Filosofía del Derecho, campo en el que pretende sentar nuevos mojones para la discusión, después de reexaminar cerca de 2.500 años de evolución del Derecho Natural; por supuesto, ha sido esta alzadura teórica la que le ha brindado una irrepetible claridad en el campo sistemático, logrando insuperables dividendos en el ámbito de la Dogmática jurídico penal.

6. Mirada la obra y la vida de Welzel desde este margen -como diría Zaffaroni- es imperioso hacer una evaluación detenida, objetiva y desapasionada, habida cuenta de que sus tesis han trascendido a las legislaciones penales, la jurisprudencia, la doctrina y la práctica judicial, a lo largo de los últimos cincuenta años, bien sea directamente o por reflejo a través de la dogmática española.

7. Si se tiene en cuenta la embestida autoritaria que hoy se vive en todo el mundo globalizado en general y, en el continente en particular, deben volverse los ojos sobre prédicas como las que difundió el catedrático de la Universidad de Bonn, después de la Segunda Guerra Mundial, para tomarlas como punto de referencia que sirva para la construcción de la democracia entre nosotros y superar un pasado lleno de injusticia y terror.

8. Finalmente, debe decirse que la actual polémica entre finalismo y funcionalismo, no puede llevar el debate a los extremos que los defensores más

83 Para Hirsch (Derecho penal, tomo I, p. 13), con Welzel murió en 1977 "probablemente el más significativo dogmático penal desde karl Binding". 
radicales del llamado "racionalismo del fin" pretenden; por el contrario, si algo está claro es que la Ciencia Jurídico-penal contemporánea tiene que nutrirse de las "viejas" y de las "nuevas" corrientes, para avanzar hacia una síntesis indispensable ${ }^{84}$, teniendo siempre como norte, eso sí, el respeto de los derechos fundamentales de la persona humana y el rechazo a los modelos de Derecho Penal autoritario que hoy se vuelven a proponer -piénsese, en el llamado "Derecho Penal de enemigo"-, en medio de un nuevo canto de sirenas que pretende que los estudiosos de estas disciplinas sepulten el pasado y abran sus brazos, acríticamente, ante "viejas" corrientes que hoy aparecen con nuevos ropajes.

\section{BIBLIOGRAFÍA}

ACHENBACH, Hans. (1974). Historische und dogmatische Grundlagen der strafrechtssystematischen Schuldlehre. Berlin: J. Schweitzer.

BUSCH, Richard. (1980). Modernas transformaciones en la Teoría del Delito. Bogotá: Temis.

BARQUÍN SANZ, Jesús. (2001). "Conversaciones: Dr. José Cerezo Mir". En: Revista Electrónica de Ciencia Penal y Criminología, $N^{\circ} 3$. Disponible en: http://criminet.ugr.es/recpc

BUSTOS RAMÍREZ, Juan. (1982) Bases críticas de un nuevo Derecho Penal. Bogotá: Temis.

(1994). Introducción al Derecho Penal. Bogotá: Temis.

CEREZO MIR, José. (2001). "La naturaleza de las cosas y su relevancia jurídica". En: Temas Fundamentales del Derecho Penal. Tomo I. Buenos Aires: Rubinzal-Culzoni Editores. pp. 39 y ss.

84 Véase Schünemann: "La relación entre ontologismo y normativismo", en Modernas tendencias, pp. 654 y ss.
"El finalismo, hoy". Temas Fundamentales del Derecho Penal. Tomo I. Buenos Aires: Rubinzal-Culzoni Editores. pp. 381 y ss.

(20039. "Ontologismo y normativismo en el finalismo de los años cincuenta". En: Revista de Derecho Penal y Criminología, 2a Época, $\mathrm{N}^{\circ}$ 12. pp. 45 y ss.

CÓRDOBA RODA, Juan. (1963). Una nueva concepción del Delito. Barcelona: Ariel.

DOHNA, Alexander Graf zu. (1958). La estructura de la Teoría del Delito. Traducción de Carlos Fontán Balestra/Eduardo Friker. Buenos Aires.

ESER, Albin Hassemer y WINFRIED BURKHARDT, Björn. (2000). Die deustsche Strafrechtswissenschaft vor der Jahrtausendwende. Rückbesinnung und Ausblick, München: Verlag C. H. Beck.

FERNÁNDEZ CARRASQUILLA, Juan (1986). Derecho Penal fundamental, Vol. 1, Segunda edición. Bogotá: Temis, 1986.

FERRAJOLI, Luigi. (1995). Derecho y razón. Traducción de Perfecto Andrés Ibáñez y colaboradores. Madrid: Trotta.

FROMMEL, Monika. (1989, mayo-agosto). "Los orígenes ideológicos de la teoría final de la acción de Welzel". Traducción de Francisco Muñoz Conde. En ADPCP. Tomo XLII, fascículo II, de 1989, Madrid. pp. 621 y ss.

GARZÓN VALDÉS, Ernesto. (1962). “El pensamiento jurídico de Hans Welzel". Introducción a: Hans Welzel más del Derecho Natural y del Positivismo Jurídico. Córdoba: Universidad Nacional de Córdoba.

GIMBERNAT ORDEIG, Enrique (1983). ¿Tiene futuro la Dogmática jurídico-penal?. Bogotá: Temis. 
HIRSCH, Hans Joachim. (1999-2000). Derecho Penal, Obras completas. Buenos Aires: Rubinzal-Culzoni.

. (2004). "Zum 100. Geburtstag von Hans Welzel". En: ZStW 116. Cuaderno 1, Berlin, Verlag Walter de Gruyter GmbH \& Co. KG. pp. 1-14.

JAKOBS, Günther. (1995). Strafrecht. Allgemeiner Teil. Die Grundlagen und die Zurechnungslehre. Berlin/New York: Walter de Gruyter. 2a ed., 1993. Derecho Penal, parte general. Madrid: Marcial Pons.

LLOBET RODRÍGUEZ, Javier. (2002). Prólogo al libro de Emiliano Borja Jiménez, Ensayos de Derecho Penal y Política Criminal. San José: Editorial Jurídica Continental. pp. 9-37.

. (2004). "Justicia Penal". En: El Estado arbitrario (La reforma procesal penal durante el nacionalsocialismo). San José: Editorial Jurídica Continental.

MARINUCCI, Giorgio (1998). El delito como "acción". Traducción de José Eduardo Sáinz-Cantero Caparrós. Barcelona: Bosch.

MARXEN, Klaus: (1974). Der Kampf gegen das liberale Strafrecht. Eine Studie zum Antiliberalismus in der Strafrechtswissenschaft der zwanziger und drei iger Jahre. Berlin: Duncker \& Humblot.

MERKEL, Paul. (1922). “Die Bestimmungen des Strafgesetzenwurfes von 1919 über die Straftat". En: ZStW, t. 43, Berlin/Leipzig, Walter de Gruyter. pp. 299 y ss.

MIR PUIG, Santiago. (1982). Introducción a las bases del Derecho Penal. Barcelona: Bosch.

MORENO HERNÁNDEZ, Moisés (1977). Die finale Handlungsbegriff und das mexikanische Strafrecht. (Tesis doctoral). Bonn.
. (2001). "Ontologismo o normativismo como base de la Dogmática Penal y de la Política Criminal". En: Modernas tendencias en la Ciencia del Derecho Penal y en la Criminología. Madrid: Universidad Nacional de Educación a Distancia. pp. 579 y ss.

MÜLLER, Ingo. (1987). Furchtbare Juristen. Die unbewältige Vergangenheit unserer Zeit, Manchen: Kindler Verlag.

MUÑOZ CONDE, Francisco. (2002) Edmund Mezger y el Derecho Penal de su tiempo. Estudios sobre el Derecho Penal en el Nacionalsocialismno. $3^{\mathrm{a}}$. ed. Valencia: Tirant Lo Blanch.

NOVOA MONREAL, Eduardo. (1982). Causalismo y finalismo en Derecho Penal, Bogotá: Temis.

POLITOFF, Sergio. (1989). “Sistema jurídico-penal y legitimación política en el Estado democrático de derecho". En: NFP. N 45. Bogotá: Temis. pp. 313 y ss.

(1984). “Adecuación social y terror en América Latina, el papel de la Justicia". En: DPC N ${ }^{\circ} 22$. Bogotá: Universidad Externado de Colombia. pp. 71 y ss.

RADBRUCH, Gustav; SCHMIDT, Eberhard y WELZEL, Hans. (1971). Derecho injusto y Derecho nulo. Introducción. Traducción y notas de José María Rodríguez Paniagua. Madrid: Aguilar.

RECASÉNS SICHES, Luis. (1963). Panorama del pensamiento jurídico en el siglo XX. Tomo II. México: Porrúa.

RODRÍGUEZ MOURULLO, Gonzalo. (1965). “El teologismo valorativo de Bettiol y el finalismo de WeIzel". En: Boletín de la Universidad Compostelana. No 73. Santiago de Compostela. pp. 191 y ss. 
RODRÍGUEZ MUÑOZ, José Arturo. (1978). La doctrina de la acción finalista. $2^{\mathrm{a}}$ ed. Valencia: Universidad de Valencia-Secretariado de Publicaciones.

ROXIN, Claus. (1997). Derecho Penal. Parte General. Tomo I. Traducción y notas de Diego Manuel Luzón Peña, Miguel Díaz y García Conlledo, Javier de Vicente Remesal, Madrid: Civitas.

(1997). Strafrecht. Allgemeiner Teil. $3^{\mathrm{a}} \mathrm{ed.}$ Tomo I. München: C. H. Beck.

. (1976). Problemas básicos del Derecho Penal. Traducción de Diego Manuel Luzón Peña. Madrid: Reus.

SANCINETTI, Marcelo A. (2003). "Profesor Dr. Hans Welzel (1904-1977, julio-agosto)". En: Revista del Colegio Público de Abogados de la capital federal. $N^{\circ} 67$ y 68. Sección "Biografías". Disponible en: www.cpacf.org.ar

Schünemann, Bernd: "La relación entre ontologismo y normativismo en la Dogmática jurídico-penal". En: Modernas tendencias en la Ciencia del Derecho Penal y en la Criminología. Madrid, Universidad Nacional de Educación a Distancia, 2.001, pp. 643 y ss.

El sistema moderno del Derecho Penal: cuestiones fundamentales. Traducción, introducción y notas de Jesús María Silva Sánchez Madrid, Tecnos, 1991.

SCHMIDT, Eberhard. (1983). Einführung in die Geschichte der deutschen Strafrechtspflege. Göttingen: Vandenhoeck \& Ruprecht.

SILVA SÁNCHEZ, Jesús María. (1992). Aproximación al Derecho Penal contemporáneo. Barcelona. Bosch.

STICHT, Oliver. (2000). Sachlogik als Naturrecht? Zur Rechtsphilosophie Hans Welzels 1904-1977. Paderburn: Schöningh.
SUÁREZ MONTES, Rodrigo Fabio. (1963). Consideraciones críticas en torno a la doctrina de la antijuridicidad en el finalismo. Madrid: Ediciones Rialp.

TJONG, Zong Uk. (1972, 20 de octubre). “Origen y fundamento de la teoría de las estructuras lógico-objetivas en el Derecho Penal". Traducción de Eugenio Raúl Zaffaroni. En: Doctrina Jurídica. La Plata. pp. 2 y ss.

VIVES ANTÓN, Tomás S. (1996). Fundamentos del Sistema Penal. Valencia: Tirant lo Blanch.

WEBER, Hellmuth von. (1982). "Para la estructuración del sistema del Derecho Penal". Traducción de Eugenio Raúl Zaffaroni. En: NFP, No 13. Bogotá: Temis. pp. 567 y ss.

Welzel, Hans: Abhandlungen zum Strafrecht und zur Rechtsphilosophie, Berlin-New York, Walter de Gruyter, 1975.

. "Ein unausrottbares mi[verständnis? Zur Interpretation der finalen Handlungslehre". En: NJW. Cuaderno 10, 1968, pp. 425 y ss. En Español: "La Doctrina de la acción finalista, hoy". Traducción de José Cerezo Mir. En: NFP No 1 . Medellín, Acosta, 1978 , pp. 60 y ss.

"Die deutsche strafrechtliche Dogmatik der letzten 100 Jahre und die finale Handlungslehre" en Js, tomo 11, noviembre de 1966, pp. 421 y ss.

(1938). "Über die Ehre von Gemeinschaften". En: ZStW. Vol. 57. pp. 28 y ss.

(1978, enero-junio). "Lo permanente y lo transitorio en la Ciencia del Derecho Penal". Traducción y notas de Moisés Moreno Hernández. En: Revista Mexicana de Ciencias Penales. Año I. México. pp. 203 y ss.

"Verdad y límites del Derecho natural". Traducción de Ernesto Garzón Valdés. En: Revista Jurídica Veracruzana. Tomo XXII N 4, Oct-Dic. 72, México, 1972, pp. 5 y ss. 
"Reflexiones sobre el libre albedrío". Traducción de José Cerezo Mir. En: ADPCP 1973. Madrid, Ministerio de Justicia, pp. 221 y ss.

"La imprudencia y los Delitos de la circulación" (De la teoría de los delitos imprudentes). Traducción de Josefina Núñez y Jorge E. de la Rúa, En: Cuadernos de los Institutos $N^{\circ}$ 84, Instituto de Derecho Penal. Facultad de Derecho y Ciencias Políticas de la Universidad Nacional de Córdoba, 1965 , pp. 113 y ss.

. (1956). "Die finale Handlungslehre und die Fahrlässigen Handlungen". En: $J Z N^{\circ}$ 10-11. pp. 316 y 317.

(1949). Um die finale Hanbdlungslehre. Eine Auseinandersetzung mit ihren Kritikern, Tübingen: Verlkag J.C.B. Mohr (Paul Siebeck).

. (1977). Introducción a la filosofía del Derecho. Traducción de Felipe González Vicén, Madrid: Biblioteca Jurídica Aguilar.

. (2002). Estudios de Derecho Penal. Traducción de Gustavo Aboso y Tealöw. Montevideo/Buenos Aires: B. de F.

(1970). Derecho Penal alemán. Traducción de Juan Bustos Ramírez y Sergio Yánez Pérez. Santiago de Chile: Editorial Jurídica de Chile.
(1956). Derecho Penal. Parte general. Traducción de Carlos Fontán Balestra y Eduardo Friker, Buenos Aires: Desalma.

(2001). El nuevo sistema del Derecho Penal. Traducción de José Cerezo Mir, Montevideo-Buenos Aires: Julio César Faria Editor.

WÜRTENBERGER, Thomas. (1965). La situazione spirituale della scienza penalistica in Germania. Traducción italiana de Mario Losano y Franco Giuffrida Répaci. Milano: Giuffrè.

ZAFFARONI, Eugenio Raúl. (2002). “¿Qué queda del finalismo en Latinoamérica?". En: en JAKOBS, SCHÜNEMANN, MORENO, ZAFFARONI: Fundamentos de la Dogmática Penal y de la Política Criminal (OntoIogismo y Normativismo). Cepolcrim-Editorial lus Poenale, pp. 115 y ss. También en: http://www.lexstricta.com/Doctrina/artìculo\%20zaffaroni.htm

(1980-1983). Tratado de Derecho Penal. Parte General. Buenos Aires: Ediar.

; ALAGIA, Alejandro; SLOKAR, Alejandro. (2002). Derecho Penal. Parte General. Buenos Aires: Ediar, $2^{\mathrm{a}}$ ed. 